\title{
Toward an Approach to Generate Forward-Looking Theories Using Systems Concepts
}

\author{
Kosheek Sewchurran and Irwin Brown \\ University of Cape Town, South Africa \\ Kosheek.sewchurran@uct.ac.za
}

\begin{abstract}
The need to generate original theory about information systems phenomena and ensure that such outputs are forward looking is an important concern. The paper gives examples of how IS project management practice and theories remain underpinned by concepts which do not map to experienced realities. The paper makes the case to use systems thinking approaches to unearth new theories to offer better explanations. In the pursuit of this goal, the paper first provides insight into the as-lived condition that makes human beings prone to being imprisoned by theories of yesteryear. This is done by discussing the role of language in cognition and theory development. In the IS literature, such discussions are limited despite the considerable attention to on types of theories and anatomies of theories. The paper claims and demonstrates why debate on theory cannot take place without explicit attention to aspects of cognition and as-lived existence. In the context of these discussions, the paper puts forward the suggestion that theoretical contributions rooted in systems concepts could allow for the emergence of forward-looking theory about IS phenomena. As a means of illuminating how to go about developing such theories, the paper provides a brief overview of how soft systems methodology and work systems method concepts can be used in a theorizing framework to achieve this. The main contributions to knowledge are two-fold. First, there is the inter-contextual coherence which is established by creating coherence between as-lived human experience, embodied cognition, theory, and language. Second, within such a context, we are able to demonstrate a pragmatic approach to generate better explanations about IS phenomena using systems concepts.
\end{abstract}

Keywords: Systems thinking, research, project management.

\section{Introduction and Background}

Human existence is caught in a cycle that Peter Checkland described as the neverending dance of theory and practice (Checkland 1999; Checkland and Holwell 1998; Checkland and Scholes 1999). Theory can be defined as "a set of welldeveloped concepts related through statements of relationship, which together constitute an integrated framework that can be used to [describe], explain, predict, [and prescribe] phenomena" (Strauss and Corbin 1998, p. 15). Concepts are the basic building blocks of theory, and are abstract representations of some reality (Strauss and Corbin 1998). 
Phenomena refer to the central ideas or events of interest related to a substantive area of study (Strauss and Corbin 1998).

At a societal level the cycle of theory informing practice and vice versa can be experienced as controlling systems of knowledge as well as aspirations to evolve knowledge paradigms. The effects of controlling systems of knowledge are constantly at play, either individually or in combination, but the effects are not always known. If we consider how current research affects or can affect the future, then we may conjecture that what we know in the present sets an organizing trajectory for what we can know in the future. Human beings, therefore, cannot know anything anew; all knowledge has some connection to the past and thus does influence the future. Research plays a key role in understanding the present in order to shape the future.

As researchers in Information Systems, we are interested in explaining the interaction between information technology and human beings. Often these interactions arise as a result of background effects (culture) that cannot be directly observed. The effects of culture can be estimated by referring to theorists such as Heidegger, Bourdieu, Latour, and Giddens. Heidegger (1962) speaks of the leveling effect of culture until it evades any questioning. Similarly, Bourdieu (1975) speaks of habitus and Latour (1999) speaks of enrolment and actor-networks. All these theorists note that cultural effects are mostly below the consciousness level. Appropriately, John Maynard Keynes suggested that people often turn out to be the intellectual prisoners of theoreticians of yesteryear (Winter and Szczepanek 2009).

As information technology permeates daily existence more and more, research in the IS field is challenged to explain more complex and abstract phenomena related to human existence and human enterprise. Scholarship in IS has long been concerned with relevance and rigor to ensure that there is acculturated progress in providing better explanations (Banville and Landry 1989; Benbasat and Zmud 2003; King and Lyytinen 2004; March and Story 2008; Niederman et al. 2009). Recently there have been concerns raised by many IS scholars about the need to develop original theory about IS phenomena. One specific call by Grover et al. (2008) and others is to build better explanations and more forward-looking theories. The purpose of this paper is to respond to this call and to prescribe how systems thinking concepts can be used in developing forward-looking theory about IS phenomena. To understand the pragmatic needs that can be served with our proposed framework we look at problems being faced in IS project management.

\subsection{IS Project Management: The Need for New Metaphors}

An IS project is commonly understood as an orchestrated process initiated by a project manager, stakeholders, and project workers on behalf of an owner to deliver a valued outcome that is unique and needs to be achieved within predetermined constraints which can include time, scope, quality, and cost (Hughes and Cotterell 2006; Richardson and Butler 2006; Schwalbe 2007). In this area, there have been sustained research efforts to improve the unacceptably high failure rates rom which IS projects tend to suffer (Hoving 2003). Frequently, IS project implementation failures are explained in the IS research literature by a lack of proper project planning, poor project management, poor project leadership, or incorrect application of project 
management practices (Kappelman et al. 2006; Kent 2006; Nelson 2007). Nelson (2007) tried to explain failures by conducting project retrospectives on 99 projects undertaken in North America. Nelson claimed that in more than half the projects, success could have been improved if there had been more attention paid to better use of best- practices in estimating, scheduling, stakeholder management, and risk management.

On the other hand, Reich et al. (2008) state that successful IS managers learn how to bravely step away from traditional "thou-shalt" forms of project practices to deliver value early by constantly reaffirming and reviewing the value being delivered with the sponsors. This suggestion of what seems to work in practice is different than the plan-driven, role separation, deterministic processes assumed in many textbooks used to train IS project practitioners and graduates (Dalcher and Brodie 2007; Fuller et al. 2008; Richardson and Butler 2006; Schwalbe 2007). In these texts the project management body of knowledge (PMBOK), a popular practice, is often epitomized as the central core that comprises project management. The same assumptions are reflected in IS research literature where contributions tend to explicitly or tacitly accept that the core basis of project management is PMBOK. It seems researchers are locked into an incorrect image of what a project is by frequently explaining that a lack of proper project planning, poor project management, poor project leadership or incorrect application of project management practices (Kappelman et al. 2006; Kent 2006; Nelson 2007) is primarily responsible for project failure.

If we look deeper, we see that the metaphorical image that gives rise to the expectations of what a project is conjures up expectations that the project has a predetermined universal form; hence it is reasonable to expect a fixed life cycle and to be diligent with application of the project life cycle (Cicmil 2006; Cicmil et al. 2006). Project participants and many researchers in Information Systems often see projects in this way and hence exclude or marginalize other explanations.

In general, what does get defined as a project is a "non-normal" set of unique tasks that are highly uncertain in total, but can be composed of relatively known stages. The extant research literature on IS project management does give a sense that there is considerable confusion about the true nature of IS project management, but this is where the debate has been for a few years. A project-driven culture has since emerged but better explanations are required to help understand the dynamics of IS projects. To allow for newer understandings to emerge, metaphors or analogies could be useful.

\subsection{Focus and Outline of the Paper}

In this paper, we argue that such abstract knowledge can be built analogically from more experience-based knowledge. We encourage an approach to develop analogical extensions from richer, more experience-based domains (Boroditsky and Ramscar 2002). We specifically argue that metaphorical conceptual structures that draw from systems concepts and ideas provide a means of addressing the call for forward-looking theory. Metaphorical representation, we argue, allows for the presentation of abstract knowledge through more commonly understood concepts. It is claimed by some that metaphors are pervasive in everyday life, not just in language but in thought and action as well. So there is some acceptance that the conceptual systems affecting how we think and act are 
metaphoric in nature (Murphy 1996). We hope to awaken researchers to this reality by offering an approach to theorizing that encourages the generation of forward- looking theory about IS phenomena using systems concepts.

A discussion of how research does and could affect the present and future has to be premised on the nature of human as-lived daily existence and cognition. Only with such an understanding can an attempt to understand how the theories we develop enable or disable particular ways of knowing be realized. In this paper, we will draw on the works of Heidegger, Bourdieu, Maturana, and Varela to give a characterization of daily as-lived experience. Once such an understanding is established, we will then explore the role of theory development in enabling and disabling further understanding. Thereafter the paper will give an account of theorizing that takes cognizance of the need to develop forward-looking theory about IS phenomena using systems concepts. We will present an approach using soft systems methodology as an example of a research framework to show how to undertake the development of better forward-looking theories.

\section{As-Lived Human Behavior}

Martin Heidegger cryptically proclaimed in his letters on humanism in 1947 that language is the house of being. In the same letter, he went on to also claim that "in its home man dwells." This is cryptic, but it points to the central role language plays in constructing reality and allowing for learning and evolution. As social creatures, human beings cycle through knowledge systems by representing (signification), reproducing (interacting), and legitimizing (observing) various types of knowledge systems. Since the beginning of time, human beings have been subjected to an ongoing trajectory of being constructed by controlling systems of knowledge.

Heidegger, Maturana, Varela, and others claim that human beings embody understanding of their environments and this allows for human beings to undertake their daily activities without necessarily being conscious of their involvement. Heidegger and others claim that human beings are not always reflective while they undertake daily mundane activities. These researchers also go on to qualify that, at times, human beings are reflective; in this mode of existence they can observe themselves undertaking the various tasks or look back and reflect on various interactions. Because human beings develop a pre-reflective sense or grasp of their environments, they thus bring to bear habituated expectations in their perceptions.

All perceptions are, however, formulated while being-in-the-world and the process is not rational nor does it present a view from nowhere (Guignon 1983). There are thus no complete or all-encompassing perspectives or facts in themselves. Human beings embody their environments and contexts, and there is always the danger of knowledge systems becoming controlling systems of thought. Human beings are thus historically conditioned to provide responses they have become socialized into; often they cannot step back from these responses and rationally alter them. As a result of this, cognition is not something that is rational and engaged with consciously. The environment is observed through the retina where images are processed by the mind during a cognitive process to compute understanding of the phenomena, together with adequate behavior for the given situation. Maturana and Varela (1998) explain that in 
the area of the retina, to which the visual image is transferred, there are hundreds of neurons from other zones of the nervous system. The retina, therefore, should not be understood as a relay station that transfers visual images as retinal stimulation to the visual cortex. Instead, the transfer to the visual cortex needs to be understood as a confluence of the visual stimulation and other stimulation coming continuously from the rest of the body (Maturana and Varela 1998).

Maturana and Varela believe that cognition is an ongoing process subservient to existential concerns. They cryptically say that "all knowing is doing; and all doing is knowing" (p. 27). Matrurana and Varela claim that the nervous system is the means by which human beings learn and store knowledge of their interactions with the environment. The human nervous system is said to interconnect the sensory and motor surfaces via the brain, providing a dynamic system of coordination between sensory and motor surfaces that is ongoing, and tied to existential concerns. Further, according to Merleau-Ponty (2002), the human being as an organism is tied to its environment in a dialectic manner such that the recurrent interactions are stored by the nervous systems as sensory-motor coupling of particular phenomena.

Phenomena, concepts, or theories that make up the reality human beings experience are said to be brought about by an act of distinction, either promoted by researchers or by human beings themselves as they learn and cope in daily existence. For the rest of the paper, the terms phenomena, concepts, and theories will be referred to collectively as a phenomenal domain. The experience of human consciousness is considered to only be possible through such phenomenal domains made possible by language. Through the use of concepts, theories, metaphors, and analogies, human beings are able to interact with their consciousness (Maturana and Varela 1998). Language, therefore, provides for the definition of various states of consciousness where individual words become tokens for linguistically coordinating actions representing bodily responses that can be triggered by the nervous system.

Consequently, linguistic behavior can be seen as a form of orienting behavior. Through linguistic means a human being can orient others and/or themselves to a phenomenal domain. Accordingly, language is said to be connotative or symbolic instead of denotative of individual entities (Maturana and Varela 1980). Because the nervous system produces coherent behavior through the generation of sets of neuronal activity that anticipate a pre-given world (Maturana and Varela 1998); the nervous system is said to always already be in a specific state, which presents a unique context for each human being. Reality is, therefore, a unique disclosure for each human being.

Since human beings largely exist with language, the acquisition of knowledge or mastery of a domain of interactions is achieved by expanding the nervous system through learning how to interact with various phenomenal domains. Such evolution then becomes constrained by the anatomical organization of the human being and language available to identify the states relevant for facilitating interaction with the phenomenal domain. Although the nervous system expands the domain of interactions of human beings, the nervous system remains subservient to the existential concerns of the human being. For this reason Maturana and Varela (1998) say the nervous system operates by structural determination because the environment triggers reactions from the human being, yet the environment cannot specify the reactions. Consciousness and mind can consequently be seen as constructions that arise from 
social interaction that human beings are capable of with themselves, other beings, and/or their environment.

As a result of this biological nature, cognitive structures are created and re-created in an infinite cycle through recurrent practices within a phenomenal domain. Heidegger believes that human beings are in a state of continual becoming until death. Given this context, his cryptic statement that language is the home of being within which man lives becomes more appreciable. From the above, it is also evident that language is central to learning and evolution in a cultural sense because phenomenal practices get stored and enriched in the nervous system throughout an individual's existence (Llewelyn 2003; Raelin 2007; Varela et al. 1993). With such a view we accept that language is both the means and median of constructing the future.

\section{Theorizing}

In accordance with the above discussion on learning and cognition, this section will present a view on how knowledge claims can generally be structured, crafted, and positioned to maximize utility and learning, and to facilitate cultural evolution. Cultural evolution occurs naturally and theoretical development should facilitate such evolution to enable human beings to mediate their changing environments with more relevant practices.

Research contributions can be defined as the development and use of theoretical concepts as a means to understand, observe, act, or bring forth a world with which to talk and interact. It is through theoretical concepts that human beings bring forth an understanding of the world. The assimilation of new concepts, therefore, depends on the ease with which they can be assimilated by the nervous system given the constraints of the existing nervous system structure. Alternatively, learning may need to dislodge conceptual phenomena already embedded in the nervous system (Llewelyn 2003). It can be inferred that there is a logical architecture to structure the phenomenal schema of the nervous system. Similarly, Varela et al. (1993) claim that a basic activity in cognition is categorization of the concepts that appear to come from the structured nature of bodily and social experiences.

In this paper, we attempt to give insight into the architecture of knowledge that human beings embody. The lens provided by Llewelyn (2003) is useful in this regard. There is also a taxonomy presented by Gregor (2006) that is widely cited in the IS literature. For our purposes, Llewelyn's work is more useful in providing a framework that gives insight into the architecture of how phenomenal domains evolve. Gregor's work classifies theories according to purpose (i.e., analysis, explanation, prediction, explanation and prediction (EP), design, and action). These are descriptions of the utility and almost assume a rational and reflective human being. This taxonomy, while useful, does not consider the nature of human understanding from the perspective of both researchers and those being researched.

It is widely established in the IS research culture that new theories have the potential to bring new phenomena into being. In IS research, there is a rich history of using theoretical lenses to emphasize particular aspects of a research problem space. Theories also serve a more mundane and practical purpose in daily interaction. For the most part, the extent to which theories are influencing reality is not consciously 
known because they serve as a resource base to provide understanding of situations or provide a basis to acquire more understanding. All such as-lived experiences represent knowing, which can be unconscious or conscious. The taxonomy developed by Llewelyn provides for five different types of theories that manifest in uncovering reality for human beings, or are available to researchers as options to craft or contextualize research contributions. These are shown in Table 1.

Table 1. Five Levels of Theorization (from Llewelyn 2003, p. 667)

\begin{tabular}{|c|l|l|}
\hline Level & \multicolumn{1}{|c|}{ Theory } & \multicolumn{1}{|c|}{ Focus } \\
\hline 1 & Metaphor theories & $\begin{array}{l}\text { As a means to ground experience. Examples of metaphors } \\
\text { are software development is a game of invention and } \\
\text { communication (Cockburn 2002). }\end{array}$ \\
\hline 2 & $\begin{array}{l}\text { Differentiation } \\
\text { theories }\end{array}$ & $\begin{array}{l}\text { Facilitate "cutting the pie" of experience. Examples of } \\
\text { differentiation theories are Maslow's hierarchy of needs or } \\
\text { the SDLC cycle. }\end{array}$ \\
\hline 3 & Concept theories & $\begin{array}{l}\text { Examples of concept theories are feminism, business } \\
\text { process change, etc. These concepts give access to a } \\
\text { phenomenal world. }\end{array}$ \\
\hline 5 & $\begin{array}{l}\text { Theories } \\
\text { focus on settings } \\
\text { structures }\end{array}$ & $\begin{array}{l}\text { Explaining how contexts for practices are organized. } \\
\text { Examples of theorizing settings are challenges in global } \\
\text { software development from a South Africa industry } \\
\text { perspective. }\end{array}$ \\
\hline
\end{tabular}

\subsection{Level 1 Metaphors}

Morgan (cited in Llewelyn 2003) argues that a metaphor is a basic structural form of experience by which human beings engage, organize, and understand their world. The organizational metaphor is a well-known way in which organizational experiences are characterized. We have come to understand organizations as machines, organisms, brains, cultures, political systems, psychic prisons, instruments of domination, etc. (Llewelyn 2003). The metaphor is a basic way in which human beings ground their experiences and continue to evolve them by adding new, related concepts that carry aspects of the original metaphor. Later on in this paper, we will argue that the holon, or world view, from a systems thinking perspective is a kind of metaphor. The grounding metaphor then plays a role in initiating the conceptual framework. Much as in systems thinking, there is a served system (holon) and the serving system, which equates to the human activity system (Checkland 1999; Checkland and Holwell 1998; Checkland and Scholes 1999). 
Llewelyn emphasizes the manner in which metaphors allow human beings to understand and experience one kind of thing in terms of another by citing Lakoff and Johnson (1980). The first example given shows that when academic researchers experience arguments as war, some of the expressions of their experiences are given as follows:

- "He attacked every weak point in my argument"

- "I demolished his argument"

- "I've never won an argument with him"

- "He shot down all my arguments"

An important part of Lakoff and Johson's analysis is that the metaphor influences both understanding, and also structures experience. To emphasize the point about metaphors, Llewellyn extends the discussion by showing that if argument is fused with debate instead of war, it was experienced as a give-and-take affair, the exchange of opinions, the realization that other points of view are necessary and everyone has a right to adopt a point of view. Through the discussion provided by Llewellyn it can be concluded that the power of a metaphor is that it provides foundational grounding in understanding of a phenomenon and any subsequent understanding has to either take cognisance of or negotiate the foundational understanding the metaphor has established. Additionally, it can also be inferred that people employ several metaphors to understand, theorize, and experience phenomena (Llewelyn 2003).

Murphy (1996), while acknowledging the pervasive effects metaphors have on imagination, also admits to the difficulty in providing a concise definition. In a structural sense Murphy claims metaphors can be used to represent abstract and complex phenomena using easier to understand domains. Therefore, there is often an attempt to present topics using various vehicles. Obviously the vehicles should not apply to the topics in straightforward or literal ways. Generally the metaphoric domain is carried by the vehicle and the concept is lit up or projected onto this domain. For example, an IS project could be understood as a temporary organization, or a language gamed instead of a life-cycle process.

\subsection{Level 2 Theorization: Differentiation}

Still ensconced in a world influenced by Cartesian dualism, a seemingly natural way by which human beings have come to understand is to adopt dualisms like in-out, presence-absence, up-down, finite-infinite, mind-body, public-private, objectivesubjective, and so on. Many of the dualisms are rooted in spatial and bodily experience. This is perhaps a basic way in which people cut up the pie of experience. As with metaphoric theorization, differentiation theorization can impede and enable new ways of thinking and doing. Differentiation theorization, therefore, aims to create meaning and significance by setting up contrasts and categories that order the world (Llewelyn 2003). In IS project management, there has been a shift from a dichotomous view of project failure and success to differentiating success for the project management process and emergent product. 


\subsection{Level 3 Theorization: Concept Theories}

Concepts are described by Llewelyn as a basic form of theorization that is used to observe and represent the world. Concepts, therefore, give rise to practices. The example given by Llewelyn is that with the introduction of feminism, women were able to see their experiences differently. Feminism as a conceptual innovation gave rise to organizations that prioritized the ideals of feminism and challenged established norms. Conceptual innovations often replace, challenge, or change existing concepts. Level 2 differentiation theories can be used to sharpen conceptual categories. For example, feminism can be positioned as two ideals: feminism in developing countries and feminism in developed countries. Such differentiation of the concepts can draw attention to slightly different realities, which call for different sets of actions, which give rise to a phenomenal domain. Concepts, then, are a basic form of theorization that are extended and sharpened using level 1 and 2 categories. In the IS project management area, newer concepts of benefits realization have emerged to draw attention to how benefits accrue over time.

\subsection{Level 4 Theorization: Theorizing Settings}

Theorizing settings is defined by Llewelyn as the strategy of theorization that defines the contextual influences on specific individual, organizational, or social phenomena. The aim of this theorization is to explain or understand the wider social conditions under which practices are produced. The social settings of practices can exist at a number of levels and are not based directly on observable phenomena, and are therefore not dependent on empiricism. This implies that non-observable structural, social, and institutional phenomena may be included. Theorizing settings or context bound theories offer an understanding of the setting for the experience.

\subsection{Level 5 Theorization: Grand Theorizing Structures}

According to Llewelyn, grand theorizing is done in the world of ideas rather than the world of practice. In grand theories, practice on the ground is always influenced by structural conditions, and these are not necessarily observable through empirical efforts. Grand theorizing is concerned with understanding relationships of power.

\section{How Soft Systems Thinking Treats the Effects of Language}

From the works of Weick $(1989,1999)$, we know that theorizing is very much a process that is dependent on teasing out understanding and striving to make explicit hitherto implicit knowledge. Theorizing is closely linked to learning and sensemaking. Soft systems methodology (SSM) is a well-known approach to learning in and about complex IS problems. Surprisingly it has not been used widely in the process of IS theorizing (Sewchurran and Petkov 2006). This may be due to the lack of understanding of the role of language in theorizing and creating reality. Conventional qualitative research methods pay some attention to language but do not give enough attention to the role of language in generating deeper explanations of the why, as is prescribed by SSM, through the articulation of world views and root definitions. 
We argue, therefore, that the use of SSM in qualitative research presents an opportunity to deepen theorizing, because it has had success in contributing to understanding situations and concerns in various other interventions.

SSM embraces a number of practices that are grounded in the assumption that language is central to learning, understanding, and behavior. First, SSM emphasizes drawing rich pictures to grasp and express the situation of concern. This emphasis on not using words is an attempt to give structure to the background conditions that give rise to the situation of concern. The value of this process is that it allows for coherent understanding of the background to emerge through symbolism. These symbols represent structural conditions that are difficult to express in words but are manifest in the situation as tacit and embodied assumptions. This first step in the expression of the situation of concern allows for learning to take place. Through discussion and participation in this exercise, stakeholder appreciation and understanding is enhanced because of the orienting effects of conversation. Perhaps the most important reason to pursue the use of SSM in research is that it makes it possible to explore and articulate world views and perspectives of why through disciplined and facilitated imagination. These world views are important because they are the analogical basis that gives rise to subsequent attitudes and reactions. Often world views are not adequately investigated or articulated in research and only characteristics of behavior are aggregated in building theories.

Efforts at empirical research often produce theoretical contributions as abstracted models that describe phenomena as concepts with predicate relationships. While these contributions have value, they are often closed off from facilitating conditions and are not connected to representations of why (Smyth and Morris 2007). We argue that these are not forward-looking enough, as they are not developed within an organizing trajectory that is guided by the relevant perspectives. This explanation would also clarify why the research framework given later in this paper provides more forward looking capability than, for example, grounded theory methods. The argument could also be made that contributions developed outside a systemic organizing trajectory will not, by design, be analogical enough to give future related findings coherence. Consequently, research efforts will more likely confound than they will aggregate and emancipate. In this paper we argue that the underlying metaphor or holons that gives rise to concepts has not been appreciated enough. There are many reasons for this. The two reasons this paper addresses are, first, there is a general lack of insight into how to structure holons as theories, and second, there is not enough emphasis placed on the value such understanding has in generating explanation. Both of these probably emerge from the general lack of appreciation for the value in using the SSM process as a research process to build theory. A suggestion of how this can be done is given in the next section.

\section{Prescription on How to Use Soft System Thinking in Research Processes}

We have been using the research framework described in this section to study IS projects and this has helped us develop this version of the method. In the context of this paper, we argue that IS project management practitioners and researchers have 
been constrained by unrealistic notions of projects. Practitioners and researchers are locked into a restricted paradigm of understanding and are having difficulty emerging from it, because narrow metaphors continue to shape experiences of projects in research and practice. From Nelson's (2007) research it is evident how research results are impacted when understanding is restricted to just the observable human activities (human-activity-system). The suggestion to use SSM as a research framework puts forward the premise that world views and root definitions provide more forward-looking explanations than theories modeled at the human activity level, such as Nelson's.

In systems thinking, especially soft systems thinking, a fundamental assumption that is made is that each person is guided by holons. An alternative way of expressing this is to say that behavior is, for the most part, perceptually guided and embodied. A holon represents the meaningful activity that is worth being pursued. It is accepted in the SSM tradition that holons are not normally readily explicable in linguistic terms as they are tacit and embodied. However, SSM promotes that holons can be teased out. SSM offers processes and devices to engage in learning to render holons explicable. It is, therefore, reasonable to expect that through SSM a linguistic realization of the concepts, analogies, and metaphors that motivate understanding or action in a particular context can be developed.

Figure 1 shows how the core abstractions of served and serving systems interrelate in the context of an information system. In systems thinking terms, the holon represents the served-system as the metaphor. This is the basic structural form which defines the essence of purposeful activity or system for a particular stakeholder, or stakeholder group. Research projects that target explanations or descriptions of served-systems could make use of SSM.

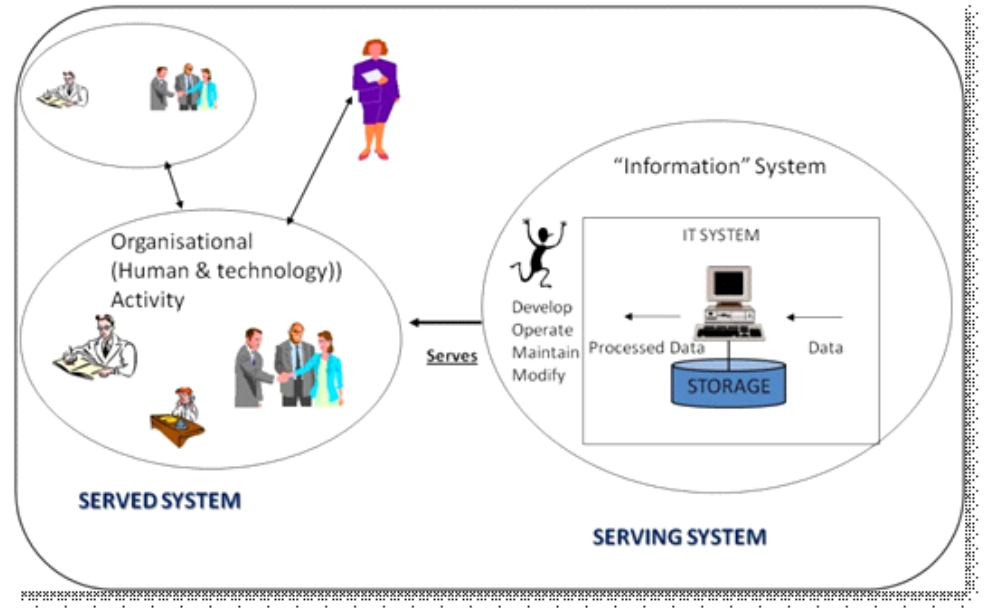

Fig. 1. Information System as Serving and Served Systems (from Checkland and Howell 1998)

Sewchurran and Barron (2008), for example, attempted to do such research to unearth the world views that characterize project experiences among project managers 
and project sponsors. The aim of their inquiry was to understand the perspectives as well as what influences the perspectives of project managers and project sponsors about how relationships are managed and sustained during the delivery of IT projects, and how the relationships ultimately impact the project outcome. The questioning was thus at the level of the served-system rather than serving-system (see Figure 1).

The served and serving systems exist and evolve in an interdependent manner as is highlighted in Figure 1. While SSM's strength has been the definition of the servedsystem the work systems method (WSM) (Alter 2002) which is a relatively new theoretical framework promises to be more rigorous and useful to describe the serving-systems. For our purposes in this paper a serving system is a work system in which human participants and/or machines perform work using IS and other resources to produce products and/or services for internal or external customers. As-lived project experiences can be described using constructs from the WSM. The WSM is both a descriptive theory and an approach (prescriptive theory) on how to think about, model and define the elements of the work systems. The approach can also be used in order to discern how serving systems relate in the context of served-systems as is highlighted in Figure 2.

The descriptions of the served and serving systems are complementary and in a research process should be undertaken together to ensure that the hermeneutic benefits materialize. If an analysis is done using WSM and SSM together, the detail of the serving system will enrich the understanding of the served systems. The understanding of the served-systems will similarly enrich the understanding of the serving-system. This will provide learning from details to abstraction in a complementary way.

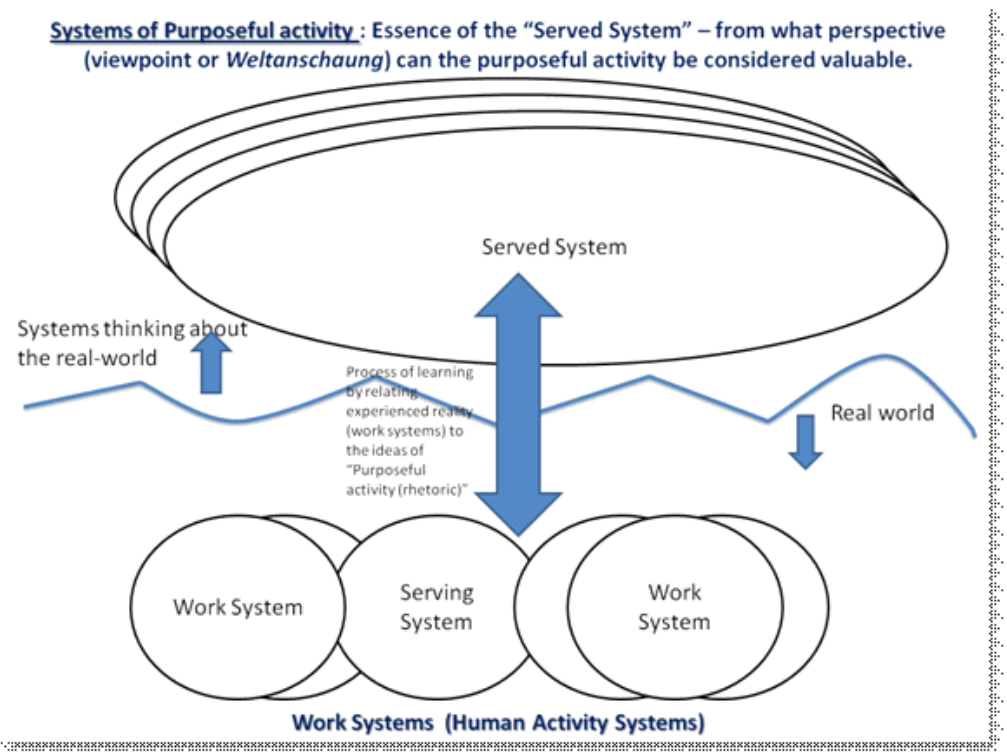

Fig. 2. The Process of Disciplined Imagination Using SSM and WSM 
The use of SSM and WSM presents an opportunity to enhance the abstracted contribution of traditional empirical qualitative research to improve the contributions' analogous value to future problems, as well as to embrace and recognize the embodied role of the researcher and those being studied. Generating forward-looking theories of IS phenomena can then be achieved using system concepts. Figure 2 shows how the two strands of research enquiry guided by the approaches of SSM and WSM can inform a research process by relating experienced reality to ideas of purposeful activity. In this manner, abstract knowledge can be built analogically from more experience-based knowledge.

The SSM technique can be used to learn about a particular situation from a group of stakeholders who have specific experience of the problem area in an instance of the more general problem. The usefulness of the findings will be dependent on careful selection of homogenous instances of the more general problem. Through focus groups or interviews, the researcher can use the SSM sense-making devices of CATWOE (customers, actors, transformation process, world view, owners, environment) analysis, root definitions (definition of systems deemed relevant to the phenomenon under investigation), and WSM concepts to make sense of the participants' ideas of what is going on, or what should go on. As the researcher progresses through interaction with selected groups of stakeholders, he/she has to relate the findings from the study back to the extant literature and feed these connections back to the study on an on-going basis-this we see as the process of disciplined imagination as described by Weick (1989).

The cycle can end arbitrarily or as soon as the findings begin to show saturation. Depending on the findings, the results may need to be categorized or stratified. It may even be necessary for the researcher to present his/her perspective as well if such insight is deemed useful. The emerging results are expected to constitute a systemic account of what is going on and/or what needs to happen from the perspective of those actors working in a common problem space. We argue that such contributions will constitute more holistic and coherent findings and will rival the current approaches of understanding phenomena through factors influencing a phenomenon or critical success factors. Better approximations of what is going on can be achieved. Such findings will also address the need for forward-looking theory as they would be imagined within an organizing trajectory that is analogical. The contributions that emerge from this research process can be structured using Llewelyn's (2003) principles, but will also fall into Gregor's (2006) taxonomy as predictive theory or explanatory-and-predictive theory.

\section{Conclusion}

In this paper, we presented an approach to using systems concepts in order to generate forward-looking theory that maximally impacts the future. We used our experience of researching IS projects to show how it is sometimes necessary to find new metaphors and analogies to underpin theory development. We first provided insight into the aslived condition that makes human beings prone to being imprisoned by theories of yesteryear to substantiate the need for forward-looking theories. Heidegger (1962) identified a type of fore-having which shapes and affects understanding that sets 
human existence and becoming along a trajectory. In this paper, we made the case that this fore-having can be estimated using SSM and WSM concepts. We presented a research framework that includes SSM and WSM to estimate this fore-having which shapes perspective and behavior. A unique feature of the research framework presented here is the disciplined imagination process that is expected to happen within an organizing trajectory led by relevant world views. We argue that such findings will be more opulent in offering insight that is forward-looking because it is imagined along the trajectory of human becoming. The research framework presented here is being used in current research projects in South Africa. We expect that our ideas of the research framework will evolve with our experiences. While this effort is only a single attempt to imagine how we can generate theory about IS phenomena and ensure that these are forward-looking, we hope we have also contributed by demonstrating the importance language, as-lived reality, and human becoming have on the debate about forward-looking theory.

\section{References}

Alter, S.: The Work System Method for Understanding Information Systems and Information Systems Research. CAIS 9, 90-104 (2002)

Banville, C., Landry, M.: Can't the Field of MIS be Disciplined? CACM 32(1), 48-60 (1989)

Benbasat, I., Zmud, R.: The Identity Crisis Within the IS Discipline: Defining and Communicating the Disciplines Core Properties. MIS Quarterly 27(2), 183-194 (2003)

Boroditsky, L., Ramscar, M.: The Role of the Body and Mind in Abstract Thought. Psychological Science 13(2), 185-189 (2002)

Bourdieu, P.: Outline of a Theory of Practice. Cambridge University Press, Cambridge (1977)

Checkland, P.: Systems Thinking, Systems Practice. Wiley, Chichester (1999)

Checkland, P., Holwell, S.: Information, Systems and Information Systems: Making Sense of the Field. Wiley, Chichester (1998)

Checkland, P., Scholes, J.: Soft Systems Methodology in Action. Wiley, Chichester (1999)

Cicmil, S.: Understanding Project Management Practice through Interpretive and Critical Research Perspectives. Project Management Journal 37(2), 27-37 (2006)

Cicmil, S., Williams, T., Thomas, J., Hodgson, D.: Rethinking Project Management: Researching the Actuality of Projects. Intl. J. of Project Management 24(8), 675-686 (2006)

Cockburn, A.: Agile Software Development. Pearson Education, Inc., Boston (2002)

Dalcher, D., Brodie, L.: Successful IT Projects. Thompson, London (2007)

Fuller, M., Valacich, J., George, J.: Information Systems Project Management: A Process Team Approach. Prentice Hall, Upper Saddle River (2008)

Gregor, S.: The Nature of Theory in Information Systems. MIS Quarterly 30(3), 611-642 (2006)

Grover, V., Lyytinen, K., Srinivasan, A., Tan, B.C.-Y.: Contributing to Rigorous and Forward Thinking Explanatory Theory. JAIS 9(2), 40-47 (2008)

Guignon, C.: Heidegger and the Problem of Knowledge. Hackett Publishing Company, Indianapolis (1983)

Heidegger, M.: Letter on Humanism. Cambridge University Press, Cambridge (1947)

Heidegger, M.: Being and Time. Harper \& Row, New York (1962)

Hoving, R.: Executive Response: Project Management Process Maturity as a Secret Weapon. MISQ Executive 2(1), 29-30 (2003) 
Hughes, B., Cotterell, M.: Software Project Management, 4th edn. McGraw-Hill Companies, London (2006)

Kappelman, L.A., McKeeman, R., Zhang, L.: Early Warning Signs of IT Project Failure: The Dominant Dozen. Information Systems Management 23(4), 31-36 (2006)

Kent, C.: The Project Management Maturity Model. Information Systems Management 23(4), 50-58 (2006)

King, J., Lyytinen, K.: Reach and Grasp. MIS Quarterly 28(4), 539-551 (2004)

Lakoff, G., Johnson, M. (eds.): Metaphors We Live By. The Production of Reality: Essays and Readings on Social Interaction. University of Chicago Press, Chicago (1980)

Latour, B.: On Recalling ANT. In: Law, J., Hassard, J. (eds.) Actor Network Theory and After, pp. 15-25. Blackwell Publishers, Oxford (1999)

Llewelyn, S.: Methodological Issues: What Counts as Theory in Qualitative Management and Accounting Research? Introducing Five Levels of Theorizing. Accounting, Auditing \& Accountability J. 16(4), 662-708 (2003)

March, S.T., Story, V.C.: Design Science in the Information Systems Discipline: An Introduction to the Special Issue on Design Science Research. MIS Quarterly 32(4), 725-730 (2008)

Maturana, H.R., Varela, F.J.: Autopoiesis and Cognition: The realization of the Living. Reidel Publishing Company, Dordrecht (1980)

Maturana, H.R., Varela, F.J.: The Tree of Knowledge: The Biological Roots of Human Understanding. Shambhala, London (1998)

Merleau-Ponty, M.: Phenomenology of Perception. Routledge, London (2002)

Morgan, G.: Images of Organizations. Sage Publications, Beverly Hills (1986)

Murphy, G.: On Metaphoric Representation. Cognition 60, 173-204 (1996)

Nelson, R.: IT Project Management: Infamous Failures, Classic Mistakes, and Best Practices. MISQ Executive 6(2), 67-78 (2007)

Niederman, F., Gregor, S., Grover, V., Lyytinen, K., Saunders, C.: ICIS 2008 Panel Report: Is Has Outgrown the Need for Reference Discipline Theories, or Has It? CAIS 24(37), 639-656 (2009)

Raelin, J.A.: Toward and Epistemology of Practice. Academy of Management Learning and Education 6(4), 495-519 (2007)

Reich, B.H., Sauer, C., Wei, S.Y.: Innovative Practices for IT Projects. Information Systems Management 25(3), 266-272 (2008)

Richardson, G., Butler, C.: Readings in Information Technology Project Management. Thompson, Boston (2006)

Schwalbe, K.: Information Technology Project Management. Thompson, Boston (2007)

Sewchurran, M., Barron, M.: An Investigation into Successfully Managing and Sustaining the Project-Sponsor Project-Manager Relationships Using Soft Systems Methodology. Project Management Journal 39, Supplement, S56-S68 (2008)

Sewchurran, M., Petkov, D.: A Systemic Framework for Business Process Modeling Combining Soft Systems Methodology and UML. Information Resources Management 20(3), 46-62 (2006)

Smyth, H.J., Morris, P.W.G.: An Epistemological Evaluation of Research into Projects and Their Management: Methodological Issues. Intl. J. of Project Management 25(4), 423-436 (2007)

Strauss, A., Corbin, J.: Basics of Qualitative Research: Techniques and Procedures for Developing, 2nd edn. Sage Publications, London (1998) 
Varela, F.J., Thompson, E., Rosch, E.: The Embodied Mind. MIT Press, Cambridge (1991)

Weick, K.: Theory Construction as Disciplined Imagination. Academy of Management Review 14(4), 516-531 (1989)

Weick, K.: What Theorizing Is Not, Theorizing Is. Administrative Science Quarterly 40, 385390 (1999)

Winter, M., Szczepanek, T.: Images of Projects. Gower, Farnham (2009)

\section{About the Authors}

Kosheek Sewchurran is an associate professor of Information Systems at the University of Cape Town and a research associate with the Centre for IT and National Development in Africa (CITANDA). He currently serves on the editorial boards of International Journal of Managing Projects in Business and International Journal of IT and the Systems Approach (IJITSA).

Irwin Brown is a professor in the Department of Information Systems at the University of Cape Town where he is also deputy dean of research in the commerce faculty. In addition, he is the director of the Centre for IT and National Development in Africa (CITANDA). He holds positions as the South African national representative of IFIP TC8 (Information Systems) and the IS subeditor of South African Computer Journal. 